\title{
Fluoride content in children's dentifrices marketed in Lima, Peru
}

Bertha Angélica CHÁVEZ ${ }^{(a)}$

Gissela Briceño VERGEL ${ }^{(a)}$

Carol Ponce CÁCERES(a)

Matheus França PERAZZO(b)

Raquel Gonçalves

VIEIRA-ANDRADE(b)

Jaime Aparecido CURY(c) (iD

(a) Maternal Perinatal Institute, Lima, Peru.

(b) Universidade Federal de Minas Gerais UFMG, Department of Pediatric Dentistry and Orthodontics, Belo Horizonte, MG, Brazil.

(c) Universidade Estadual de Campinas - Unicamp, Piracicaba Dental School,

Piracicaba, SP, Brazil.
Abstract: The aim of the present study was to determine the concentration of total fluoride (TF) and total soluble fluoride (TSF) in children's dentifrices marketed in the city of Lima, Peru. Three samples of 23 dentifrices (4 without fluoride and 19 with fluoride) were purchased in different pharmacies in Lima, Peru. The TF and TSF concentrations found in the dentifrices were determined by ion-selective electrode, expressed in ppm F ( $\mu \mathrm{g} \mathrm{F} / \mathrm{g}$ of dentifrice). The $\mathrm{TF}$ concentration in the majority of the fluoride toothpastes matched that shown on the label, except for one declared as $1450 \mathrm{ppm} F$ by the manufacturer, whereas only 515.1 ppm F was found. The concentration of TSF found in the fluoride toothpastes ranged from 457.5 to 1134.8 ppm F. All the dentifrices were formulated with silica, but one also presented calcium carbonate. In conclusion, $83 \%$ of the children's dentifrices marketed in Lima, Peru, were fluoridated, but only 53\% contained a TSF concentration greater than 1000 ppm F, the minimum concentration required to provide an anticaries effect.

Keywords: Fluorides; Pediatric Dentistry; Toothpastes.

\section{Introduction}

Declaration of Interests: The authors certify that they have no commercial or associative interest that represents a conflict of interest in connection with the manuscript.

Corresponding Author:

Bertha Angelica Chávez

E-mail: angelicachavez2008@hotmail.com

https://doi.org/10.1590/1807-3107bor-2019.vol33.0051

Submitted: December 21, 2018

Accepted for publication: April 30, 2019

Last revision: May 22, 2019
The use of toothpaste with fluoride has been recommended for over 50 years to prevent and control dental caries. ${ }^{1}$ Topical fluoride is considered one of the most effective public healthcare strategies to control caries, especially among the child population, which is the most vulnerable. ${ }^{2}$ The anticaries effect of fluoride toothpastes, together with the correct toothbrushing technique, promotes the disruption of biofilm, and maintains the demineralization-remineralization balance. ${ }^{3}$ An amount of $1000 \mathrm{ppm}$ of $\mathrm{F}$ in toothpaste achieves this benefit, but the $\mathrm{F}$ must be in soluble form (SF) for it to be active in its formulation, and thus be able to interfere in the development of a disease. . $^{1,4,6,6,7,8}$

The presence of SF in a dentifrice depends on its formulation, in terms of type of fluoride salt and abrasive used. The dentifrices that contain sodium fluoride $(\mathrm{NaF})$ have high fluoride availability, because they are formulated with silica as an abrasive agent. When the toothpaste is formulated with an abrasive containing calcium (calcium carbonate or dicalcium phosphate dihydrate), it must contain sodium monofluorophosphate (MFP) as a fluoridating agent, because the MFP ion does not react immediately with $\mathrm{Ca}^{++} .6,9$ However, this type of formulation 
is not totally stable, and the F concentration decreases by $40 \%$ one year after manufacture. For this reason, it is better not to purchase a product, if it does not show an expiration date..$^{6,10,11}$

The recommendations for fluoride toothpaste use in infants and children have been modified in recent years in an effort to maximize caries prevention, and minimize the risk of dental fluorosis ${ }^{1}$. Some healthcare professionals put off using of fluoridated dentifrice in children; this is an inappropriate approach, since there is no scientific evidence to conclude that the use of fluoridated dentifrices in children under 12 months of age is associated with fluorosis. ${ }^{2,12}$ On the other hand, recommending dentifrices without $F$ or with a low F concentration to avoid fluorosis is irresponsible, since the at-home application of $\mathrm{F}$ through toothpaste is the best public healthcare strategy to prevent and control caries. ${ }^{13,14}$ Scientific evidence indicates that fluoridated toothpaste should be used as soon as the first tooth appears in the oral cavity. ${ }^{13}$ Therefore, it is up to pediatric health professionals to make recommendations regarding toothpaste expiration dates and minimum amount of $\mathrm{F}$ for an anticaries effect, especially in areas where fluoridated drinking water is not available. ${ }^{15,16}$

The regulations made by some countries, such as the US and Mercosur member countries, do not require companies to state the amount of SF in a given product. ${ }^{2}$ Peru is subject to Sanitary Technical Standard 2001 regulating the addition of fluorides to toothpastes, approved by M.R. No. 454-2001-SA/ $\mathrm{DM}$, which states merely that toothpastes for children must have an SF concentration of less than 600 ppm one year after being manufactured, and $450 \mathrm{ppm}$ until their expiration. ${ }^{17}$ The last Peruvian study that evaluated the concentration and stability of fluoride was published in the mid-twentieth century. ${ }^{18}$

Considering the importance of the SF concentration in toothpastes, it was decided to evaluate this concentration in children's dentifrices marketed in the city of Lima, Peru, and to compare it with the information declared by the manufacturer on the packaging label, in order to substantiate information that guarantees the anticaries effect of dentifrices.

\section{Methodology}

Twenty-three dentifrices marketed for children's use and found in different pharmacy chains in the city of Lima, Peru, during the period from June to July 2017, were purchased in triplicate of different batches (total $=69$ ). The samples were coded to allow blind analysis. The manufacturer's information about the dentifrices are described in Table 1.

In regard to chemical analysis, total soluble fluoride (TSF or free F) concentrations were determined, including $\mathrm{F}$ ion (FI) and fluoride as sodium monofluorophosphate (MFP), and total fluoride (TF), corresponding to the sum of TSF and insoluble F (IF), which may be bound to the abrasive. Ninety to $110 \mathrm{mg}$ of each dentifrice $( \pm 0.01 \mathrm{mg})$ were weighed and homogenized vigorously in $10.0 \mathrm{ml}$ of deionized water. An aliquot of $0.25 \mathrm{ml}$ of the suspension was transferred from each toothpaste tube (total $=69$ ) to TF-labeled test tubes, and $0.25 \mathrm{ml}$ of $2 \mathrm{M} \mathrm{HCl}$ was added. The tubes were heated to $45^{\circ} \mathrm{C}$ and kept at this temperature for 1 hour to hydrolyze the MFP ion to the $\mathrm{F}$ ion, and to dissolve the IF bound to the abrasive.

The resulting acid suspension was neutralized with $0.5 \mathrm{ml}$ of $1 \mathrm{M} \mathrm{NaOH}$, and buffered with $1 \mathrm{ml}$ of TISAB II (1 M acetate buffer, $\mathrm{pH}$ 5.0, containing $1 \mathrm{M} \mathrm{NaCl}$ and $0.4 \%$ CDTA). The suspension was centrifuged for 10 min to $3000 \mathrm{~g}$ at room temperature to remove the IF, and the supernatant was used to determine TSF and IF. Afterwards, $0.25 \mathrm{ml}$ of the supernatant was transferred to tubes labeled as TSF, and treated as described for TF. The F concentrations in the tubes (TF and TSF) were evaluated using an $F$ electrode (Thermo Scientific Orion 96-09, Orion Research, Cambridge, MA, USA), coupled to an ion analyzer (Star A214, ThermoScientific Orion). The electrode was calibrated with standard $\mathrm{F}$ solutions from 0.06 to $8.0 \mu \mathrm{g} \mathrm{F} / \mathrm{mL}$, prepared in $0.25 \mathrm{M}$ $\mathrm{NaOH}, 0.25 \mathrm{M} \mathrm{HCl}$ and TISAB II 50\% (v/v). A linear regression between the logarithm of $\mathrm{F}$ concentrations in standard and respective $\mathrm{mV}$ values was determined using Excel software (Microsoft, Redmond, USA). The mathematical regression equation was used to calculate the concentration of $\mathrm{F}$ in dentifrice (Figure 1). Using the determined amounts of TF and TSF, the IF concentration was calculated as TF - TSF, and the percentage of IF was obtained by dividing the IF concentration by TF, 
Table 1. Information regarding the dentifrices analyzed (Lima, Peru).

\begin{tabular}{|c|c|c|c|c|c|c|c|}
\hline Sample & Name & $\begin{array}{l}\text { Fluoride declared } \\
\text { on packaging } \\
\text { (ppm) }\end{array}$ & $\begin{array}{c}\text { Active } \\
\text { ingredient }\end{array}$ & $\begin{array}{l}\text { Abrasive specified on } \\
\text { packaging }\end{array}$ & $\begin{array}{l}\text { Manufacture } \\
\text { date }\end{array}$ & $\begin{array}{c}\text { Expiration } \\
\text { date }\end{array}$ & $\begin{array}{l}\text { Country of } \\
\text { manufacture }\end{array}$ \\
\hline A & Denture BB & Without fluoride & Lacking & Silica, hydrated silica & Jul 16 & Jul 19 & Ecuador \\
\hline B & Dentito Baby & Without fluoride & Lacking & Silica & Apr 17 & Aug 19 & Peru \\
\hline C & Aquafresh Baby teeth & Without fluoride & Lacking & Silica & Not specified & Apr 18 & USA \\
\hline D & Colgate My First & Without fluoride & Lacking & Hydrated silica & Not specified & Oct 17 & USA \\
\hline$E$ & Farma Dent Kids & 452 & $\mathrm{NaF}$ & Silica & Not specified & Jul 21 & China \\
\hline$F$ & $\begin{array}{c}\text { Colgate Smiles (Sponge } \\
\text { Bob, Barbie) }\end{array}$ & 500 & $\mathrm{NaF}$ & Hydrated silica & Not specified & Jan 20 & Mexico \\
\hline G & Denture Kids & Not specified & MFP & Silica & Aug 16 & Aug 19 & Ecuador \\
\hline $\mathrm{H}$ & Aquafresh Little Teeth & 500 & $\mathrm{NaF}$ & Hydrated silica & Not specified & Jan 18 & USA \\
\hline । & $\begin{array}{c}\text { Oral B Stages (Frozen, } \\
\text { Star Wars, Princesses, } \\
\text { Mickey Mouse) }\end{array}$ & 500 & $\mathrm{NaF}$ & Hydrated silica & Oct 16 & Sep 18 & Mexico \\
\hline J & Dentito gum flavor & 550 & MFP & Silica & Not specified & May 20 & Peru \\
\hline K & $\begin{array}{l}\text { Dentito Chicha Morada } \\
\text { flavor }\end{array}$ & 550 & MFP & Silica & Not specified & Mar 20 & Peru \\
\hline $\mathrm{L}$ & Tuinies Hello Kitty & 580 & $\mathrm{NaF}$ & Hydrated silica & Not specified & Jul 20 & China \\
\hline M & Tuinies Peppa Pig & 1450 & $\mathrm{NaF}$ & Hydrated silica & Not specified & Jun 21 & China \\
\hline N & Oral B 123 & 1000 & $\mathrm{NaF}$ & Hydrated silica & Not specified & Jun 18 & Mexico \\
\hline O & $\begin{array}{c}\text { Dento Junior watermelon } \\
\text { flavor }\end{array}$ & 1100 & $\mathrm{NaF}$ & Silica & Not specified & Oct 19 & Peru \\
\hline$P$ & $\begin{array}{c}\text { Colgate Kids strawberry } \\
\text { flavor }\end{array}$ & 1100 & $\mathrm{NaF}$ & Hydrated silica & Not specified & Feb 20 & Brazil \\
\hline Q & Ipana & 1100 & $\mathrm{NaF}$ & Hydrated silica & Not specified & Feb 20 & Peru \\
\hline R & Colgate Kids grape flavor & 1100 & $\mathrm{NaF}$ & Hydrated silica & Not specified & Feb 20 & Brazil \\
\hline S & $\begin{array}{l}\text { Colgate Smiles (Barbie, } \\
\text { Minions, Spiderman) }\end{array}$ & 1100 & $\mathrm{NaF}$ & Hydrated silica & Not specified & Feb 20 & Mexico \\
\hline $\mathrm{T}$ & $\begin{array}{c}\text { Colgate Kids tutti-frutti } \\
\text { flavor }\end{array}$ & 1100 & $\mathrm{NaF}$ & Hydrated silica & Not specified & Feb 20 & Brazil \\
\hline U & $\begin{array}{c}\text { Tuinies Hello Kitty-Xtreme } \\
\text { White }\end{array}$ & 1450 & $\begin{array}{l}\mathrm{NaF} \\
\mathrm{MFP}\end{array}$ & Hydrated silica & Not specified & July 20 & China \\
\hline V & Vitis Junior & 1000 & $\mathrm{NaF}$ & Silica & Not specified & Dec 19 & Spain \\
\hline W & Aquafresh "My Big Teeth" & 1150 & $\mathrm{NaF}$ & Hydrated silica & Not specified & Feb 19 & USA \\
\hline
\end{tabular}

NaF: Sodium fluoride; MFP: Sodium monofluorophosphate (MFP $=\mathrm{Na}_{2} \mathrm{FPO}_{3}$ ).

and multiplying by 100 . The analysis of each tube of toothpaste was carried out in triplicate.

The data were reported by the biochemistry laboratory of the School of Dentistry, University of Piracicaba (Unicamp), Brazil, and were processed according to an automated tabulation method, after which an analysis of frequency was performed according to the objectives specified.

\section{Results}

The 23 dentifrices analyzed in this study included four dentifrices without $\mathrm{F}$, one with an unspecified concentration of $\mathrm{F}$, and 18 with $\mathrm{F}$ concentrations from 452 to $1450 \mathrm{ppm}$. The main active ingredients used were $\mathrm{NaF}$, present in 15 of the analyzed samples, and MFP, present in three; one sample contained both active ingredients (NaF and MFP) (Table 1). In relation to the 


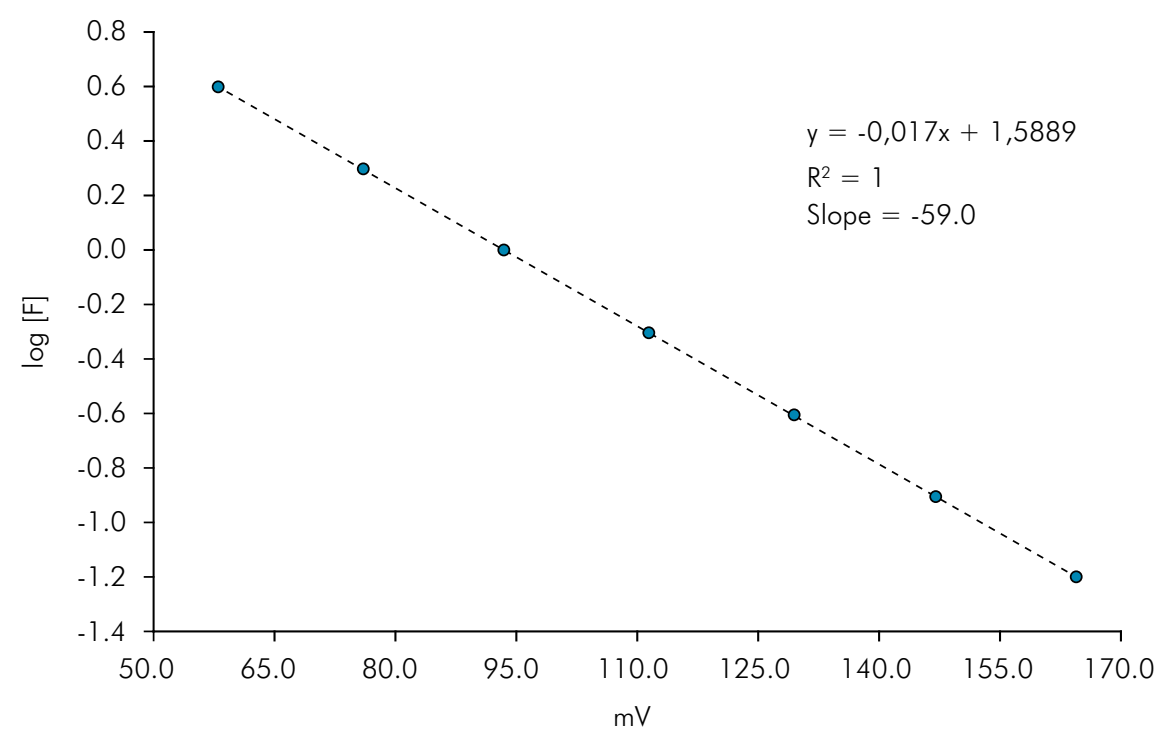

Figure 1. Calibration curve $(n=4)$ and data on the correlation between the logarithm of fluoride concentrations in the standard and relative $\mathrm{mV}$ values generated

abrasives reported on the packaging, the most common were silica and hydrated silica. The abrasive agents declared by the manufacturer matched those found, except for Sample U (Tuinies Hello Kitty Extreme White), whose packaging indicated silica, but whose analysis revealed calcium carbonate. The expiration date was informed on all the products; however, the manufacture date was reported on just four.

The TF concentration declared on the packaging of 21 of the 23 dentifrices analyzed in this study was close to the value found (Table 2 and Figure 2). Only Denture Kids toothpaste (Sample G) did not declare any $\mathrm{F}$ content on the packaging, but the analysis found an amount of $476.4( \pm 2.8)$ ppm of F in its composition. In addition, Tuinies Peppa Pig toothpaste (Sample M) declared a concentration of $1450 \mathrm{ppm}$ of $\mathrm{F}$ in its composition, whereas the laboratory analysis revealed a concentration of only 515.1 ( \pm 10.5$)$ ppm of F.

Furthermore, we found that the average concentration of TF was slightly lower than the concentration of TSF in 18 of the 19 fluoridated dentifrices analyzed. Only the Tuinies Hello Kitty - Xtreme White sample (Sample U) showed a concentration of TF $(1,307.6 \pm 22.3)$ greater than TSF $(1,061.4 \pm 56.1)$. Almost $20 \%$ of the TF of this formulation is insoluble (Table 2). Although the label indicates that the abrasive is silica, we checked and were surprised to find that the abrasive was calcium carbonate, not silica. In regard to the dentifrices claiming they did not contain $\mathrm{F}$ ( $17 \%$ of the total dentifrices analyzed), the information declared is similar to what was actually found. Of the 23 dentifrices analyzed, 53\% $(n=13)$ showed that a minimum concentration of $F$ had a high anticaries potential (Table 3 and Figure 3 ).

\section{Discussion}

The therapeutic efficacy of a toothpaste is based on the release of fluoride into the oral environment at the time of brushing; for this reason, its formula must provide SF. ${ }^{19-21}$ In our study, only $53 \%$ of the samples had the minimum concentration needed to promote an anticaries effect (1,000 ppm).

Sample G (Denture Kids) does not state the concentration of $\mathrm{F}$ on the packaging, and the analysis showed 492.1 ppm of F, whereas SampleM(Tuinies Peppa Pig) states 1,400 ppm F, with the analysis showing only $38 \%$ of the value declared (531 ppm F). A discordant value was also found in the study by Giacaman et al. ${ }^{16}$ (Chile), who found a dentifrice whose amount of $\mathrm{F}$ declared by the manufacturer was 450 ppm, whereas the amount of $\mathrm{F}$ found exceeded this amount threefold.

These discordant values between the $F$ declared by the manufacturer on the packaging and the $\mathrm{F}$ 
Table 2. As declared on label: total fluoride (TF) and total soluble fluoride (TSF) concentration ( $\mathrm{mg} \mathrm{F} / \mathrm{kg}$ ) found, and \% of insoluble fluoride (IF) in the dentifrices analyzed (average $\pm s d ; n=3$ ).

\begin{tabular}{|c|c|c|c|c|c|}
\hline Sample & Dentifrice & Expected TF (ppm) & TF found & TSF found & IF (\%) \\
\hline A & Denture BB & Without fluoride & $0.0 \pm 0.0$ & $0.0 \pm 0.0$ & na \\
\hline B & Dentito Baby & Without fluoride & $0.0 \pm 0.0$ & $0.0 \pm 0.0$ & na \\
\hline C & Aquafresh Baby Teeth & Without fluoride & $0.0 \pm 0.0$ & $0.0 \pm 0.0$ & na \\
\hline D & Colgate My First & Without fluoride & $0.0 \pm 0.0$ & $0.0 \pm 0.0$ & na \\
\hline$E$ & Farma Dent Kids & 452 & $428.3 \pm 1.5$ & $457.5 \pm 10.5$ & 0.0 \\
\hline $\mathrm{F}$ & Colgate Smiles (Sponge Bob, Barbie) & 500 & $472.3 \pm 7.7$ & $489.6 \pm 2.0$ & 0.0 \\
\hline G & Denture Kids & Not specified & $476.4 \pm 2.8$ & $492.1 \pm 5.7$ & 0.0 \\
\hline $\mathrm{H}$ & Aquafresh Little Teeth & 500 & $477.3 \pm 29.3$ & $481.8 \pm 13.2$ & 0.0 \\
\hline I & $\begin{array}{c}\text { Oral B Stages (Frozen, Star Wars, Princesses, } \\
\text { Mickey Mouse) }\end{array}$ & 500 & $479.1 \pm 5.6$ & $499.1 \pm 6.5$ & 0.0 \\
\hline J & Dentito gum flavor & 550 & $510.0 \pm 9.3$ & $551.7 \pm 9.8$ & 0.0 \\
\hline K & Dentito Chicha Morada flavor & 550 & $512,6 \pm 8.2$ & $550.6 \pm 15.6$ & 0.0 \\
\hline $\mathrm{L}$ & Tuinies Hello Kitty & 580 & $514.7 \pm 19.4$ & $541.4 \pm 20.6$ & 0.0 \\
\hline M & Tuinies Peppa Pig & 1450 & $515.1 \pm 10.5$ & $531.0 \pm 8.6$ & 0.0 \\
\hline $\mathrm{N}$ & Oral B 1-2-3 & 1000 & $1017.2 \pm 8.6$ & $1055.0 \pm 7.6$ & 0.0 \\
\hline O & Dento Junior watermelon flavor & 1100 & $1022.8 \pm 46.5$ & $1063.7 \pm 35.7$ & 0.0 \\
\hline$P$ & Colgate Kids strawberry flavor & 1100 & $1055.5 \pm 58.1$ & $1134.8 \pm 52.1$ & 0.0 \\
\hline Q & Ipana & 1100 & $1056.5 \pm 21.1$ & $1104.1 \pm 16.5$ & 0.0 \\
\hline $\mathrm{R}$ & Colgate Kids Grape & 1100 & $1058.5 \pm 21.1$ & $1081.7 \pm 9.0$ & 0.0 \\
\hline S & Colgate Smiles (Barbie, Minions, Spiderman) & 1100 & $1065.7 \pm 15.4$ & $1093.9 \pm 5.6$ & 0.0 \\
\hline $\mathrm{T}$ & Colgate Kids tutti-frutti flavor & 1100 & $1085.9 \pm 16.8$ & $1127.9 \pm 13.9$ & 0.0 \\
\hline$U$ & Tuinies Hello Kitty - Xtreme White & 1450 & $1307.6 \pm 22.3$ & $1061.4 \pm 56.1$ & 18.8 \\
\hline V & Vitis Junior & 1000 & $982.4 \pm 18.6$ & $1001.1 \pm 4.9$ & 0.0 \\
\hline W & W Aquafresh "My Big Teeth" & 1150 & $1069.1 \pm 6.7$ & $1112.2 \pm 13.1$ & 0.0 \\
\hline
\end{tabular}

TF: Total fluoride; TSF: Total soluble fluoride; IF: Insoluble fluoride.

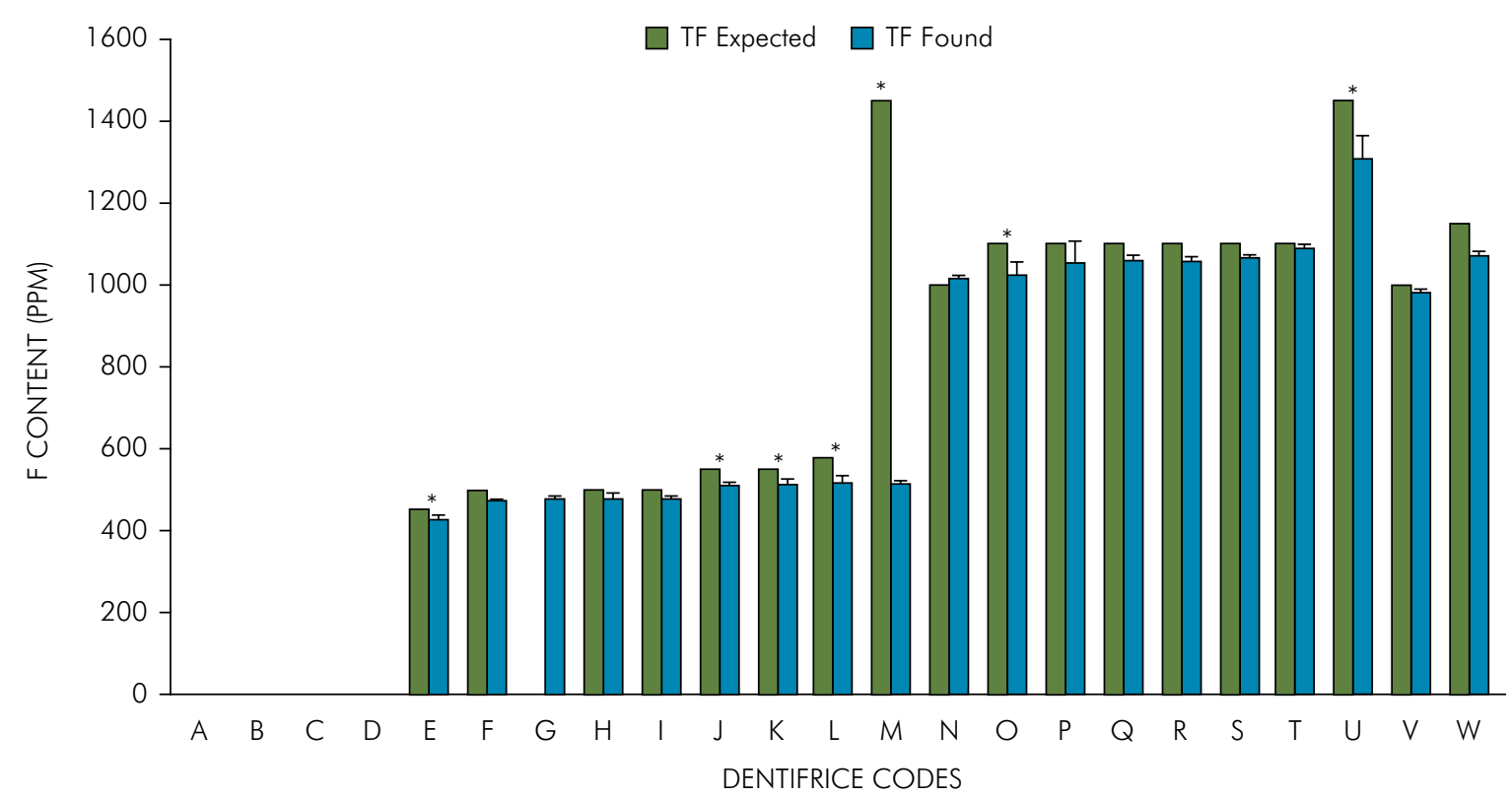

*Diference between TF found and expected of analytical signivicance ( $\pm 5 \%$ ).

Figure 2. Concentration (ppm F) of total fluoride declared by the manufacturer (TF expected) and found in the toothpastes analyzed (TF found) 
Table 3. Concentration of total soluble fluoride (average $\pm s d ; n=3$ ) in the dentifrices analyzed, and their anticaries potentials.

\begin{tabular}{|c|c|c|c|}
\hline Sample & Dentifrice & Average TSF found ( \pm sd) & Anticaries potential \\
\hline A & Denture BB & $0.0 \pm 0.0$ & None \\
\hline B & Dentito Baby & $0.0 \pm 0.0$ & None \\
\hline C & Aquafresh Baby Teeth & $0.0 \pm 0.0$ & None \\
\hline D & Colgate My First & $0.0 \pm 0.0$ & None \\
\hline $\mathrm{E}$ & Farma Dent Kids & $457.5 \pm 10.5$ & Low \\
\hline $\mathrm{F}$ & Colgate Smiles (Sponge Bob, Barbie) & $489.6 \pm 2.0$ & Low \\
\hline G & Denture Kids & $492.1 \pm 5.7$ & Low \\
\hline $\mathrm{H}$ & Aquafresh Little Teeth & $481.8 \pm 13.2$ & Low \\
\hline । & Oral B Stages (Frozen, Star Wars, Princesses, Mickey Mouse) & $499.1 \pm 6.5$ & Low \\
\hline J & Dentito gum flavor & $551.7 \pm 9.8$ & Low \\
\hline K & Dentito Chicha Morada flavor & $550.6 \pm 15.6$ & Low \\
\hline L & Tuinies Hello Kitty & $541.4 \pm 20.6$ & Low \\
\hline M & Tuinies Peppa Pig & $531.0 \pm 8.6$ & Low \\
\hline N & Oral B 1-2-3 & $1055.0 \pm 7.6$ & High \\
\hline O & Dento Junior watermelon flavor & $1063.7 \pm 35.7$ & High \\
\hline$P$ & Colgate Kids strawberry flavor & $1134.8 \pm 52.1$ & High \\
\hline Q & Ipana & $1104.1 \pm 16.5$ & High \\
\hline R & Colgate Kids Grape & $1081.7 \pm 9.0$ & High \\
\hline S & Colgate Smiles (Barbie, Minions, Spiderman) & $1093.9 \pm 5.6$ & High \\
\hline $\mathrm{T}$ & Colgate Kids tutti-frutti flavor & $1127.9 \pm 13.9$ & High \\
\hline U & Hello Kitty - Xtreme White & $1061.4 \pm 56.1$ & High \\
\hline V & Vitis Junior & $1001.1 \pm 4.9$ & High \\
\hline W & W Aquafresh "My Big Teeth" & $1112.2 \pm 13.1$ & High \\
\hline
\end{tabular}

TSF: Total soluble fluoride.

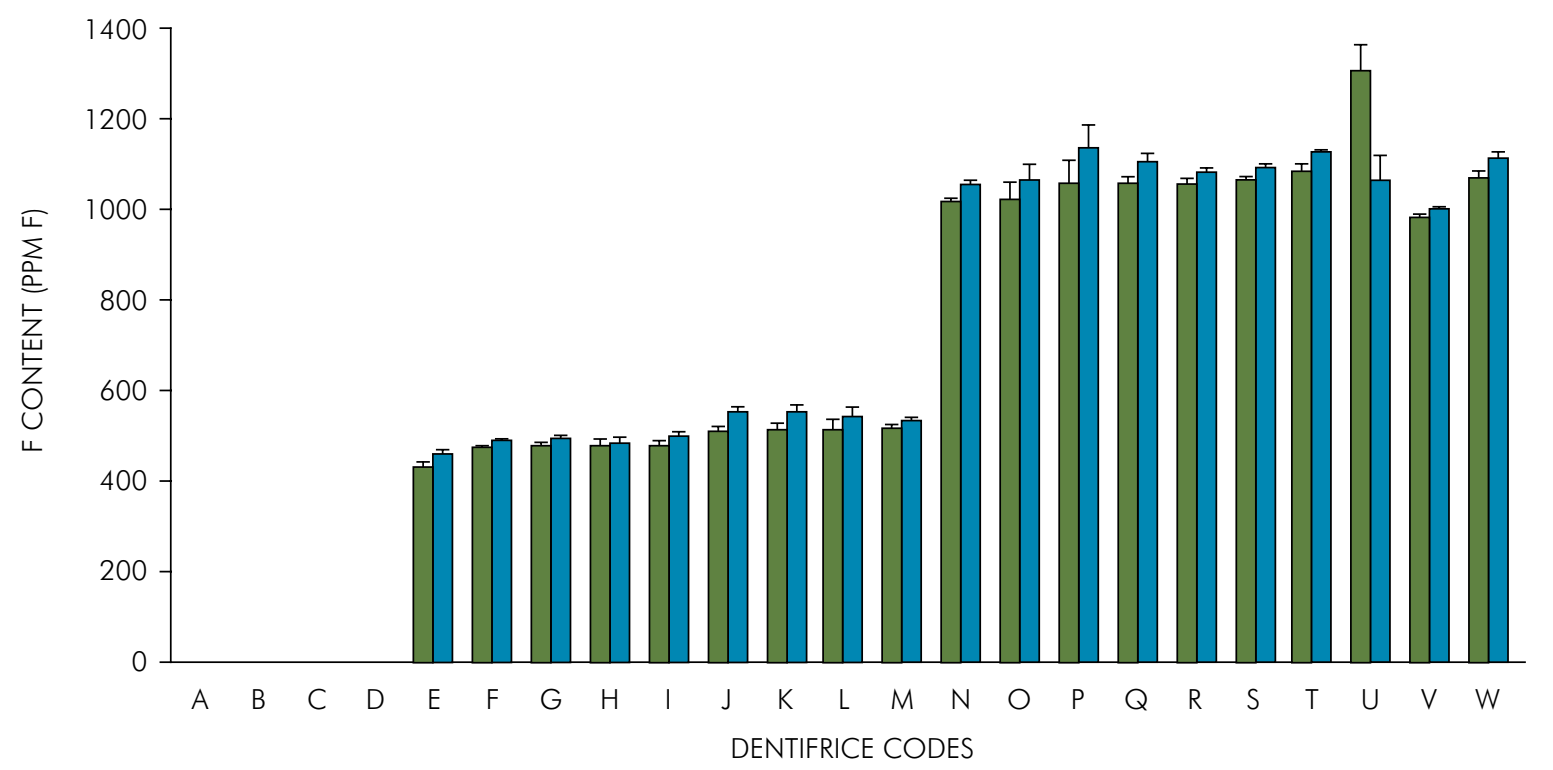

Figure 3. Concentration (ppm F) of total fluoride (TF found) and total soluble fluoride found (TSF found) in the toothpastes analyzed. 
analyzed are seriously prejudicial to consumers, since this misinformation violates their right to truthful information. It is troublesome that the products do not reflect the real value. In 17 (73.9\%) dentifrices analyzed, the TF declared by the manufacturer on the label was lower than that found. This percentage contrasts with that of Cury et al. ${ }^{2}$ and Loureiro et al., ${ }^{22}$ who found a respective $84.4 \%$ and $83.3 \%$ similarity between the F declared and the F found in Brazilian dentifrices. Nevertheless, the similarity in values found by Carrera et al. ${ }^{23}$ was $77.2 \%$ between the $\mathrm{F}$ declared and the F found. On the other hand, in a study ${ }^{24}$ with 22 fluoride toothpastes commercially available in South Africa, the TF concentration of all the toothpastes was lower than that declared by the manufacturers, with one in four having TSF concentrations of less than 1,000 ppm F.

As for the active ingredients used, the type of $\mathrm{F}$ declared on the dentifrices coincides $100 \%$ with that found in the analysis. In silica-based preparations of $1000 \mathrm{ppm}$ of F, NaF constitutes $0.22 \%$ of the dentifrice and is highly ionizable; therefore, it becomes active as soon as it enters the mouth, stimulating the remineralization of decalcified enamel and interfering in the growth and development of bacteria in dental plaque. ${ }^{20} \mathrm{NaF}$ was present in $70 \%$ of the samples analyzed (E, F, H, I, L, M, N, O, P, Q, R, S, T, V, W), and MFP, in $30 \%$ of the samples $(G, J, K)$. These results agree with those of Loureiro's study ${ }^{22}$ in Uruguay, in which most of the dentifrices that he evaluated were found to use $\mathrm{NaF}$. A previous study ${ }^{25}$ developed with toothpastes on the Belgian market, using a specific method to determine the amount of $\mathrm{NaF}$, sodium monofluorophosphate (SMFP) and amine fluoride (AmF), also found all the samples analyzed to be in conformity with the local guidelines. However, the maximum total fluoride concentration allowed by European guidelines is $0.15 \%$ (1,500 ppm F).

Regarding the active ingredient used, only Sample U (Tuinies Hello Kitty - Xtreme White) uses two types of $\mathrm{F}$ (MFP and NaF), similar to the findings of the study by Benzian ${ }^{26}$ in Brunei, Cambodia, Laos, the Netherlands and Suriname, in which two dentifrices were found to combine MFP and NaF. Most silica-based toothpastes contain highly ionizable $\mathrm{NaF}$, which is activated as soon as it comes into contact with the tooth surface. If $\mathrm{NaF}$ is combined with a calcium carbonatebased abrasive agent, it binds to the calcium of the abrasive agent, forming calcium fluoride $\left(\mathrm{CaF}_{2}\right)$ inside the toothpaste tube and not on the tooth surface. In this case, the $\mathrm{CaF}_{2}$ formed in the toothpaste does not release $\mathrm{F}$, thus inhibiting its preventive action.

Abrasives can include silica, hydrated silica and calcium carbonate (or dicalcium phosphate dihydrate). It is important to note that dentifrices containing calcium carbonate or dicalcium phosphate dihydrate as an abrasive must be formulated with MFP, whereas NaF-based ones must have silica (hydrated silica) as their abrasive agent. In this study, the abrasive appearing on the packaging was mostly hydrated silica: $61 \%$, followed by silica: $35 \%$, and both: $4 \%$. According to the label, toothpaste U (Tuinies Hello Kitty - Xtreme White) was formulated adequately with a NaF/MFP silica-based abrasive, but we found that the abrasive was actually calcium carbonate. This is explainable, because we found $20 \%$ of IF in this formulation. A study developed with toothpastes marketed in India ${ }^{27}$ also found that the mean percentage of TSF concentration in $\mathrm{SMFP} / \mathrm{CaCO}_{3}$ - (calcium carbonate) based toothpastes was $86 \%$ (SD $=16 \%$ ), whereas that in NaF/Si- (silica) based toothpastes was 98\% SD 1\%, and that in the remaining toothpastes with unknown abrasive was 95\% SD 1\%.

The present study provides results that can contribute to modifying the current guidelines that regulate the concentration of children's toothpaste marketed in Peru. The last national caries survey found a prevalence of dental caries in deciduous, mixed and permanent dentitions of $59.1 \%, 85.5 \%$ and $57.6 \%$, respectively. ${ }^{28}$ Pertinent changes in the Peruvian regulations on adequate $\mathrm{F}$ concentration could guarantee the use of toothpastes that effectively control dental caries. ${ }^{29,30}$ Accordingly, it could reduce the polarization of dental caries according to socioeconomic status, since children from low-income families usually have more dental caries than those with a higher income. ${ }^{30}$ In addition, the prevention of oral conditions can minimize social, functional, economic and behavioral impacts on children and/or parents. ${ }^{29,30,31}$

The present results are an alert for other regions of the world having resolutions that lack guidelines on the beneficial anticaries effect of fluoride, as 
in Mercosur countries. ${ }^{32}$ Knowing the benefit of toothpastes with adequate concentrations of fluoride allows effective strategies to be established to control caries. In addition, the present study shows that the Peruvian health surveillance system fails to control imported dentifrices from China, corroborating a previous analysis on the dentifrice market in Chile. ${ }^{16}$

\section{Conclusion}

Most of the children's dentifrices marketed in Lima, Peru, at the time of this study, were fluoridated, but only $53 \%$ contained a TSF concentration greater than $1000 \mathrm{ppm} \mathrm{F}$, the minimum concentration needed to provide an anticaries effect. Therefore, the concentrations of $\mathrm{F}$ in toothpastes for children in Lima seem inappropriate for dental caries control, and must be rectified in public health policies.

\section{Acknowledgements}

We are grateful to Mr. Waldomiro Vieira Filho, from the Oral Biochemistry Laboratory, FOPUNICAMP, for his technical analysis. This study was supported by the Federal University of Minas Gerais (UFMG) and financed in part by the Coordenação de Aperfeiçoamento de Pessoal de Nível Superior Brasil (CAPES) - Finance Code 001.

\section{References}

1. Wright JT, Hanson N, Ristic H, Whall CW, Estrich CG, Zentz RR. Fluoride toothpaste efficacy and safety in children younger than 6 years: a systematic review. J Am Dent Assoc. 2014 Feb;145(2):182-9. https://doi.org/10.14219/jada.2013.37

2. Cury JA, Oliveira MJ, Martins CC, Tenuta LM, Paiva SM. Available fluoride in toothpastes used by Brazilian children. Braz Dent J. 2010;21(5):396-400. https://doi.org/10.1590/S0103-64402010000500003

3. Noronha MS, Romão DA, Cury JA, Tabchoury CP. Effect of fluoride concentration on reduction of enamel demineralization according to the cariogenic challenge. Braz Dent J. 2016 Jul-Aug;27(4):393-8. https://doi.org/10.1590/0103-6440201600831

4. Santos AP, Oliveira BH, Nadanovsky P. Effects of low and standard fluoride toothpastes on caries and fluorosis: systematic review and meta-analysis. Caries Res. 2013;47(5):382-90. https://doi.org/10.1159/000348492

5. dos Santos AP, Nadanovsky P, Oliveira BH. A systematic review and meta-analysis of the effects of fluoride toothpastes on the prevention of dental caries in the primary dentition of preschool children. Community Dent Oral Epidemiol. 2013 Feb;41(1):1-12. https://doi.org/10.1111/j.1600-0528.2012.00708.x

6. Cury JA, Dantas ED, Tenuta LM, Romão DA, Tabchoury CP, Nóbrega DF, et al. Fluoride concentration in most sold MFP/CaCO3 - based Brazilian toothpastes at the expiration time. Rev Assoc Paul Cir Dent. 2015 Jul/Sep;69(3):248-51.

7. Walsh T, Worthington HV, Glenny AM, Appelbe P, Marinho VC, Shi X. Fluoride toothpastes of different concentrations for preventing dental caries in children and adolescents. Cochrane Database Syst Rev. 2010 Jan;(1):CD007868. https://doi.org/10.1002/14651858.CD007868.pub2

8. Costa CM, Carlo F, Sampaio F, Forte F. fluoride concentration in commercial brands of dentifrices available in the state of Paraíba, Brazil. Pesq Bras Odontoped Clin Integr. 2013 Oct/Dec;13(4):323-7. https://doi.org/10.4034/PBOCl.2013.134.04

9. Yaghini J, Kiani S, Mortazavi S, Haghshenas B, Mogharehabed A. Assessment of available and stable fluoride in four widely-used toothpastes in the Iranian market. J Dent (Tehran). 2014 Sep;11(5):604-9.

10. Sebastian ST, Siddanna S. Total and Free Fluoride Concentration in Various Brands of Toothpaste Marketed in India. J Clin Diagn Res. 2015 Oct;9(10):ZC09-12. https://doi.org/10.7860/JCDR/2015/13382.6578

11. Veeresh DJ, Wadgave U. Assessment of total and soluble fluoride content in commercial dentifrices in Davangere: a cross sectional survey. J Indian Assoc Public Health Dent. 2014 Oct/Dec;12(4):320-2. https://doi.org/10.4103/2319-5932.147679

12. Tenuta LM, Cury JA. Fluoride: its role in dentistry. Braz Oral Res. 2010;24 Suppl 1:9-17. https://doi.org/10.1590/S1806-83242010000500003

13. Bergamo ET, Barbana M, Terada RS, Cury JA, Fujimaki M. Fluoride concentrations in the water of Maringá, Brazil, considering the benefit/risk balance of caries and fluorosis. Braz Oral Res. 2015;29(1):47. https://doi.org/10.1590/1807-3107BOR-2015.vol29.0047

14. Wennhall I, Matsson L, Schröder U, Twetman S. Outcome of an oral health outreach programme for preschool children in a low socioeconomic multicultural area. Int J Paediatr Dent. 2008 Mar;18(2):84-90. https://doi.org/10.1111/i.1365-263X.2007.00903.X

15. Balaban R, Aguiar CM, da Silva Araúio AC, Dias Filho EB. Knowledge of paediatricians regarding child oral health. Int J Paediatr Dent. 2012 Jul;22(4):286-91. https://doi.org/10.1111/j.1365-263X.2011.01196.x 
16. Giacaman RA, Carrera CA, Muñoz-Sandoval C, Fernandez C, Cury JA. Fluoride content in toothpastes commercialized for children in Chile and discussion on professional recommendations of use. Int J Paediatr Dent. 2013 Mar;23(2):77-83. https://doi.org/10.1111/j.1365-263X.2012.01226.x

17. Ministerio de Salud (Perú). Resolución ministerial 154-2001- SA/DM. Chile: Ministerio de Salud; 2001.

18. Sarmiento RV, Issáo M, Cury JA. A study on the availability and stability of fluoride dentifrices commercialized in Peru. Rev Estomatol Hered. 1994;4(1/2):12-20.

19. Oliveira MJ, Martins CC, Paiva SM, Tenuta LM, Cury JA. Estimated fluoride doses from toothpastes should be based on total soluble fluoride. Int J Environ Res Public Health. 2013 Nov;10(11):5726-36. https://doi.org/10.3390/ijerph10115726

20. Rosales JC, Cardoso DC, Chaires IC, Mejía MA. Dentífricos fluorados: composición. Vertientes Rev Especializada Cienc Salud. 2014;17(2):114-9.

21. Fernández CE, Carrera CA, Muñoz-Sandoval C, Cury JA, Giacaman RA. Stability of chemically available fluoride in Chilean toothpastes. Int J Paediatr Dent. 2017 Nov;27(6):496-505. https://doi.org/10.1111/ipd.12288

22. Loureiro LA, Fager AF, Santos Moreira MJ, Maltz M, Hashizume LN. Fluoride availability and stability in children's toothpastes in Uruguay. J Dent Child (Chic). 2017 May;84(2):52-7.

23. Carrera CA, Giacaman RA, Muñoz-Sandoval C, Cury JA. Total and soluble fluoride content in commercial dentifrices in Chile. Acta Odontol Scand. 2012 Dec;70(6):583-8. https://doi.org/10.3109/00016357.2011.640287

24. Vorster L, Naidoo S, Stauf N, Holmgren C, Benzian H. Fluoride content of toothpastes available in South Africa. Community Dent Health. 2018 Aug;35(3):186-92. https://doi.org/10.1922/CDH_4294Vorster07PMID:30106524

25. Borremans M, Van Loco J, Van Den Meerssche P, Meunier J, Vrindts E, Goeyens L. Analysis of fluoride in toothpastes on the Belgian market. Int J Cosmet Sci. 2008 Apr;30(2):145-52. https://doi.org/10.1111/j.1468-2494.2008.00425.x

26. Benzian H, Holmgren C, Buijs M, van Loveren C, van der Weiiden F, van Palenstein Helderman W. Total and free available fluoride in toothpastes in Brunei, Cambodia, Laos, the Netherlands and Suriname. Int Dent J. 2012 Aug;62(4):213-21. https://doi.org/10.1111/i.1875-595X.2012.00116.x

27. Thakkar VP, Rao A, Rajesh G, Shenoy R, Pai M. Fluoride content and labelling of toothpastes marketed in India. Community Dent Health. 2015 Sep;32(3):170-3.

28. Ministério de Salud (Peru). Guía técnica: guía de práctica clínica para la prevención, diagnóstico y tratamiento de la caries dental em niñas y niños. Dirección de Salud Bucal. Lima: Ministério de Salud; 2017.

29. Cury JM, Caldarelli PG, Tenuta LM. Necessity to review the Brazilian regulation about fluoride toothpastes. Rev Saude Publica. 2015 Dec;49:74-80. https://doi.org/10.1590/S0034-8910.2015049005768

30. Perazzo MF, Gomes MC, Neves ÉT, Martins CC, Paiva SM, Costa EM, et al. Oral problems and quality of life of preschool children: self-reports of children and perception of parents/caregivers. Eur J Oral Sci. 2017 Aug;125(4):272-9. https://doi.org/10.1111/eos.12359

31. Jensen $O$, Gabre P, Sköld UM, Birkhed D. Fluoride toothpaste and toothbrushing; knowledge, attitudes and behaviour among Swedish adolescents and adults. Swed Dent J. 2011;35(4):203-13.

32. Ribeiro GL, Gomes MC, Lima KC, Martins CC, Paiva SM, Granville-Garcia AF. The potential financial impact of oral health problems in the families of preschool children. Ciênc Saúde Coletiva. 2016 Apr;21(4):1217-26. https://doi.org/10.1590/1413-81232015214.09512015 